\title{
Three-Year Follow-Up of High-Dose Ubiquinol Supplementation in a Case of Familial Multiple System Atrophy with Compound Heterozygous $\mathrm{COQ} 2$ Mutations
}

\author{
Jun Mitsui ${ }^{1}$ Ken Koguchi ${ }^{2}$ Toshimitsu Momose ${ }^{3}$ - Miwako Takahashi ${ }^{3}$. \\ Takashi Matsukawa $^{1} \cdot$ Tsutomu Yasuda $^{1} \cdot$ Shin-ichi Tokushige $^{1} \cdot$ Hiroyuki Ishiura $^{1}$. \\ Jun Goto $^{1}$ - Shigeaki Nakazaki ${ }^{2}$ - Tomoyoshi Kondo ${ }^{4}$ - Hidefumi Ito ${ }^{5}$ •

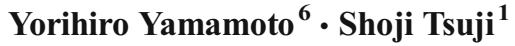

Published online: 1 February 2017

(C) The Author(s) 2017. This article is published with open access at Springerlink.com

\begin{abstract}
We report a 3-year follow-up of high-dose ubiquinol supplementation in a case of familial multiple system atrophy (MSA) with compound heterozygous nonsense (R387X) and missense (V393A) mutations in COQ2. A highdose ubiquinol supplementation substantially increased total coenzyme $\mathrm{Q}_{10}$ levels in cerebrospinal fluid as well as in plasma. The patient was at the advanced stage of MSA, and the various scores of clinical rating scales remained stable without changes during the 3 years. The cerebral metabolic ratio of oxygen measured by ${ }^{15} \mathrm{O}_{2}$ PET, however, increased by approximately $30 \%$ after administration of ubiquinol, suggesting that ubiquinol can improve mitochondrial oxidative metabolism in the brain. It also suggests the therapeutic potential of ubiquinol for patients with MSA with COQ2 mutations. Further clinical trials of administration of high-dose ubiquinol to MSA patients are warranted.
\end{abstract}

Shoji Tsuji

tsuji@m.u-tokyo.ac.jp

1 Department of Neurology, Graduate School of Medicine, University of Tokyo, 7-3-1 Hongo, Bunkyo, Tokyo 113-8655, Japan

2 Department of Neurology, Shirahama Hamayu Hospital, Wakayama, Japan

3 Department of Radiology, Graduate School of Medicine, University of Tokyo, Tokyo, Japan

4 Department of Neurology, Rehabilitation Hananoie Hospital, Tochigi, Japan

5 Department of Neurology, Wakayama Medical University, Wakayama, Japan

6 School of Bioscience and Biotechnology, Tokyo University of Technology, Tokyo, Japan
Keywords Multiple system atrophy $\cdot C O Q 2$ - Coenzyme $\mathrm{Q}_{10} \cdot$ Ubiquinol

\section{Introduction}

Multiple system atrophy (MSA) is a progressive neurodegenerative disease clinically characterized by autonomic failure in addition to various combinations of parkinsonism, cerebellar ataxia, and pyramidal dysfunction [1]. Whole-genome sequence analysis in combination with linkage analysis has revealed homozygous or compound heterozygous mutations in $C O Q 2$ in two of the six multiplex Japanese families with MSA [2]. COQ2 encodes an enzyme in the biosynthetic pathway of coenzyme $\mathrm{Q}_{10}\left(\mathrm{CoQ}_{10}\right)$ [3]. Indeed, the total $\mathrm{CoQ}_{10}$ levels in frozen brain tissues and lymphoblastoid cell lines from patients with MSA carrying homozygous (M128VV393A/M128V-V393A) and compound heterozygous mutations (R387X/V393A) were substantially lower than those from control subjects [2]. These observations suggest the efficacy of $\mathrm{CoQ}_{10}$ supplementation for patients with MSA, in particular, for those with $C O Q 2$ mutations.

$\mathrm{CoQ}_{10}$ is a lipophilic molecule that functions as an essential carrier for electron transport in the mitochondrial respiratory chain and as an endogenous antioxidant [4]. Patients with primary $\mathrm{CoQ}_{10}$ deficiency, a severer phenotype than MSA, caused by genetic defects in genes involved in the $\mathrm{CoQ}_{10}$ biosynthetic pathway, have been reported to respond well to $\mathrm{CoQ}_{10}$ supplementation [5-11]. Herein, we present the detailed clinical features of a patient with familial MSA carrying compound heterozygous COQ2 mutations (R387X/V393A) [2] and report the outcome of a high-dose ubiquinol (reduced form of $\mathrm{CoQ}_{10}$ ) supplementation to this patient. 


\section{Materials and Methods}

\section{Patient}

The patient, a 60-year-old male, is an affected member of a previously described Japanese multiplex family with MSA (II-4 in Family 12) [2]. He carried compound heterozygous nonsense (R387X, c.1159C $>\mathrm{T}$ ) and missense (V393A, c.1178T $>$ C) mutations in COQ2 (NM_015697.7) [2, 12].

The patient gradually noticed slurring of speech, unsteadiness of gait, increased urinary frequency, and erectile dysfunction at the age of 44. Examination at the age of 45 revealed jerky pursuit of eye movements, gazeevoked nystagmus, and scanning speech. Lower limb movements were uncoordinated when performing the heel-knee-shin test. His gait was ataxic, and he was unable to perform tandem gait. He had urinary urgency, frequent urination, and erectile dysfunction. He also had frequent orthostatic symptoms attributable to hypotension. His cognition and visual acuity were normal. Brain magnetic resonance imaging (MRI) showed the hot cross bun sign in the pontine base and mild atrophy of the pons and cerebellum. He was then diagnosed as having "familial MSA" because his elder sister had a similar presentation with dysarthria and unsteady gait with the onset at the age of 50. She died at the age of 61. He started intermittent catheterization at the age of 47 and had frequent orthostatic symptoms once a week at the age of 48 . He became wheelchair-bound at the age of 50 and subsequently became bed-ridden owing to his severe orthostatic symptoms. At the age of 56, his speech was unintelligible most of the time due to the severe ataxic dysarthria. At the age of 58, endoscopic gastrostomy and laryngotracheal separation were performed owing to his recurrent aspiration pneumonia. At the age of 59 , his renal function gradually worsened (serum creatinine level, $1.0-1.5 \mathrm{mg} / \mathrm{dl})$.

\section{Study Design}

An open-label dose escalation trial for this patient with familial MSA with compound heterozygous COQ2 mutations (R387X/V393A) was designed to evaluate the safety and tolerability of high-dose ubiquinol, to assess pharmacokinetics, and to obtain the clinical data including the scores of clinical rating scales [Barthel Index [13], Scale for the Assessment and Rating of Ataxia (SARA) [14], International Cooperative Ataxia Rating Scale (ICARS) [15], and Unified Multiple System Atrophy
Rating Scale (UMSARS) [16]]. Positron emission tomography (PET) was carried out to measure the cerebral blood flow $(\mathrm{CBF})$ and the cerebral metabolic rate of oxygen $\left(\mathrm{CMRO}_{2}\right)$. The protocol of this study (UMIN000010712) was reviewed and approved by the institutional review board of the participating institutions. Informed consent was obtained from the patient and his legal representative prior to the initiation of this study, in accordance with the Declaration of Helsinki. Ubiquinol in the powder form (Kaneka QH ubiquinol) was provided by Kaneka Corporation (Tokyo, Japan) and was administered via a gastrostomy tube.

After baseline assessment, supplementation was started at $600 \mathrm{mg}$ of ubiquinol/day (given once a day), with the dosage increased to $840 \mathrm{mg} /$ day at week 2 and to $1200 \mathrm{mg} / \mathrm{day}$ at week 6 . The $1200-\mathrm{mg} /$ day dosage was maintained until week 8 . When no adverse events were observed during this period, the patient resumed taking $1200 \mathrm{mg}$ of ubiquinol/day after an interval of 8 weeks and remained taking ubiquinol at this same dose for over 3 years to date.

\section{Biochemical Analysis}

Peripheral blood was collected into heparinized tubes to obtain plasma samples. BD Vacutainer CPT Cell Preparation Tubes (BD, Franklin Lakes, NJ) with sodium heparin were used for separation of peripheral blood mononuclear cells (PBMCs). The total $\mathrm{CoQ}_{10}$ levels (sum of ubiquinol and ubiquinone levels) in plasma, PBMCs, and cerebrospinal fluid (CSF) were measured by high-performance liquid chromatography (HPLC) with electrochemical detection (ECD) [17] or with tandemmass spectrometry (LC-MS/MS). For measurement of the total $\mathrm{CoQ}_{10}$ level in CSF by HPLC with ECD, $400 \mu \mathrm{l}$ of CSF was mixed with $1600 \mu \mathrm{l}$ of isopropanol. An aliquot of $1500 \mu \mathrm{l}$ was evaporated to dryness and resolved in $120 \mu \mathrm{l}$ of isopropanol and $30 \mu \mathrm{l}$ of distilled water. An aliquot of $80 \mu \mathrm{l}$ of the supernatant was directly injected onto the HPLC equipped with the separation column (SHISEIDO CQ-S: $150 \mathrm{~mm} \times 2.0 \mathrm{~mm}$ I.D.) with the mobile phase of $50 \mathrm{mM}$ sodium perchlorate in methanol/ distilled water $(95 / 5, v / v)$. Measurement of the total $\mathrm{CoQ}_{10}$ level in additional CSF samples obtained after 12,24 , and 36 months of ubiquinol supplementation was conducted as follows. Twenty microliters of CSF was diluted to $5 \mathrm{ml}$ with phosphate-buffered saline and mixed with $8 \mathrm{ml}$ of diethyl ether and $10 \mu \mathrm{l}$ of internal standard solution $\left(200 \mathrm{ng} / \mathrm{ml}\right.$ of $\mathrm{CoQ}_{8}$ in isopropanol). After the solution was vigorously mixed, the supernatant separated 
by centrifugation was evaporated to dryness and resolved in $20 \mu \mathrm{l}$ of isopropanol. Quantitation of $\mathrm{CoQ}_{10}$ was accomplished by LC-MS/MS using Nexera X2 and LCMS8060 (Shimadzu, Japan).

\section{Measurement of the CBF and the $\mathrm{CMRO}_{2}$ by PET}

PET studies were carried out with ${ }^{15} \mathrm{O}$-labeled tracers $\left({ }^{15} \mathrm{O}_{2}, \mathrm{C}^{15} \mathrm{O}_{2}\right.$, and $\left.\mathrm{C}^{15} \mathrm{O}\right)$. The $\mathrm{C}^{15} \mathrm{O}_{2}$ and ${ }^{15} \mathrm{O}_{2}$ steadystate methods were used to measure the $\mathrm{CBF}$ and $\mathrm{CMRO}_{2}$, respectively $[18,19]$. PET scanning was performed during $\mathrm{C}^{15} \mathrm{O}_{2}(370 \mathrm{MBq} / \mathrm{min})$ or ${ }^{15} \mathrm{O}_{2}$ (740 MBq/min) gas inhalation after equilibrium had been reached. $\mathrm{C}^{15} \mathrm{O}$ PET $(1110 \mathrm{MBq} / \mathrm{min})$ was performed to measure cerebral blood volume (CBV) that was used for correction of $\mathrm{CMRO}_{2}$ [19-21]. PET imaging was performed using a PET scanner (Headtome/SET2400 W, Shimadzu).

For quantitative analysis, brain PET images before and after ubiquinol supplementation were intrasubjectively coregistered and morphologically normalized to the brain PET template using statistical parametric mapping 8 and MATLAB version R2014a (MathWorks Inc., Natick, MA, USA). The regions of interest (ROIs) were manually placed on the cortical ribbon of the upper frontal, lower frontal, Rolandic, lateral and medial parietal, temporal, and occipital areas and on the striatum, thalamus, cerebellar hemisphere, and cerebellar vermis on the morphologically normalized CBF PET images obtained before supplementation. These ROIs were automatically applied to other PET images, and each ROI value was then computationally calculated.

\section{Results}

\section{Ubiquinol Supplementation and Clinical Outcome}

The analysis of the total $\mathrm{CoQ}_{10}$ levels in plasma and PBMCs revealed a significant increase after 2 weeks of ubiquinol supplementation at $600 \mathrm{mg} /$ day (Table 1). The total $\mathrm{CoQ}_{10}$ levels in plasma and PBMCs remained similar for another 4 weeks at $840 \mathrm{mg} /$ day, and a subsequent 2-week administration of ubiquinol at $1200 \mathrm{mg}$ /day led to substantial increases in the total $\mathrm{CoQ}_{10}$ levels in the plasma and the PBMCs. The CoQ 10 level in CSF increased from 0.22 to $3.79 \mathrm{ng} / \mathrm{ml}$ after 2 weeks of $840 \mathrm{mg} /$ day, and a similar level of $3.64 \mathrm{ng} / \mathrm{ml}$ was observed after 2 weeks of $1200 \mathrm{mg} /$ day. Eight weeks after the last supplementation of ubiquinol, the total $\mathrm{CoQ}_{10}$ levels in plasma, PBMCs, and CSF returned to baseline levels.

Since we did not observe any adverse events at $1200 \mathrm{mg} /$ day dosage and ubiquinol supplementation at $1200 \mathrm{mg}$ /day led to higher total $\mathrm{CoQ}_{10}$ levels in the plasma and the PBMCs compared with those observed with $840 \mathrm{mg} /$ day, we

Table 1 Biochemical analyses

Total $\mathrm{CoQ}_{10}(\mu \mathrm{g} / \mathrm{ml})$ in plasma Total $\mathrm{CoQ}_{10} /$ free cholesterol Total $\mathrm{CoQ}_{10}$ in $\mathrm{CSF}(\mu \mathrm{g} / \mathrm{ml})$ in PBMCs $(\mathrm{nM} / \mathrm{mM})$

\begin{tabular}{|c|c|c|c|}
\hline Reference (mean, standard deviation, number of controls) & $\begin{array}{l}0.72 \\
0.42 \\
n=39 \\
\text { (healthy controls) }[31]\end{array}$ & Not available & $\begin{array}{l}0.35 \times 10^{-3}, \\
0.20 \times 10^{-3} \\
n=23 \\
\text { (disease controls) }\end{array}$ \\
\hline Before supplementation & 0.33 & 281 & $0.22 \times 10^{-3}$ \\
\hline After 2 weeks of $600 \mathrm{mg} /$ day & 5.04 & 1493 & Not tested \\
\hline After 2 weeks of $840 \mathrm{mg} /$ day & 4.02 & 1344 & $3.79 \times 10^{-3}$ \\
\hline After 4 weeks of $840 \mathrm{mg} /$ day & 4.43 & 1636 & Not tested \\
\hline After 2 weeks of $1200 \mathrm{mg} /$ day & 7.86 & 2047 & $3.64 \times 10^{-3}$ \\
\hline After 8 weeks of discontinuation & 0.48 & 467 & $0.25 \times 10^{-3}$ \\
\hline After 6 months of $1200 \mathrm{mg} /$ day & 4.15 & 1894 & Not tested \\
\hline After 12 months of $1200 \mathrm{mg} /$ day & 7.62 & 1891 & $7.36 \times 10^{-3 a}$ \\
\hline After 24 months of $1200 \mathrm{mg} /$ day & 4.92 & Not tested & $9.14 \times 10^{-3 a}$ \\
\hline After 36 months of $1200 \mathrm{mg} /$ day & 4.78 & Not tested & $14.06 \times 10^{-3 a}$ \\
\hline
\end{tabular}

Total $\mathrm{CoQ}_{10}$, ubiquinol + ubiquinone

${ }^{\mathrm{a}}$ Measured by LC-MS/MS 
Fig. 1 Summary of clinical course with ubiquinol supplementation. After the baseline assessment, the patient was started on ubiquinol at $600 \mathrm{mg} /$ day (given once a day), with the dose increased to $840 \mathrm{mg} /$ day at week 2 and to $1200 \mathrm{mg} /$ day at week 6 . The $1200-\mathrm{mg} /$ day dose was maintained until week 8 . After an interval of 8 weeks, the patient resumed taking ubiquinol at $1200 \mathrm{mg} /$ day. To date, he remains taking ubiquinol at this same dose for over 3 years. $B W$ body weight, $s C r e$ serum creatinine level
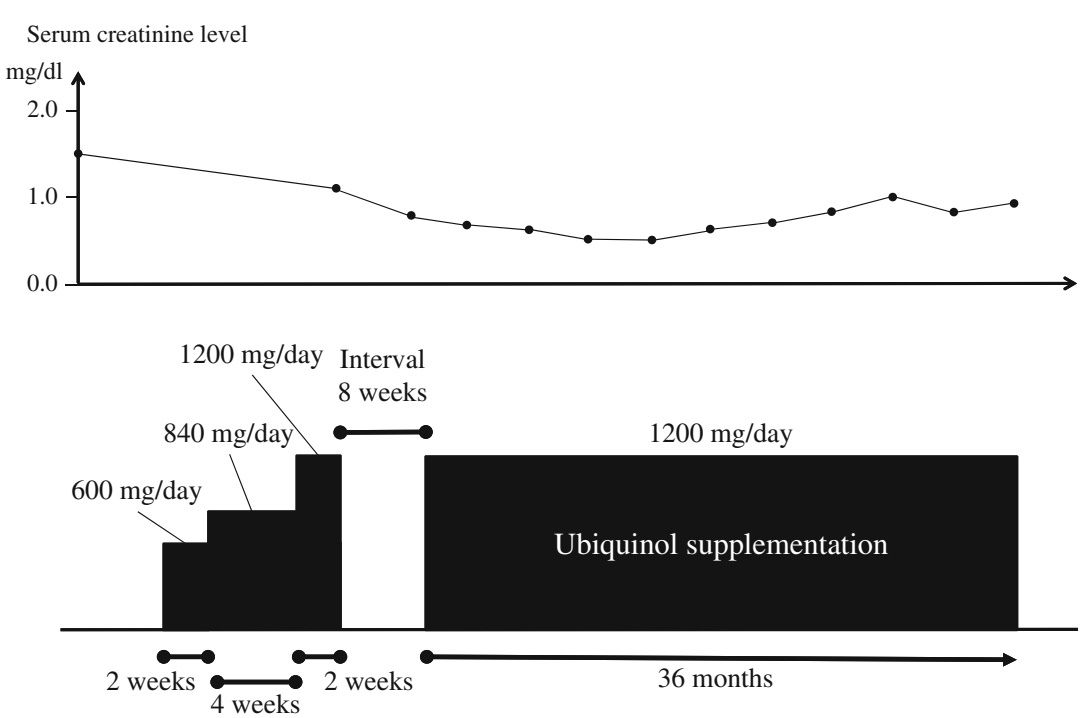

decided to maintain the 1200-mg/day dosage. After supplementation of $1200 \mathrm{mg} /$ day was resumed, the $\mathrm{CoQ}_{10}$ levels in plasma and PBMCs returned to levels similar to those observed after the initial 2 weeks of $1200 \mathrm{mg} /$ day and maintained at similar levels throughout the following period. The $\mathrm{CoQ}_{10}$ levels in CSF were $7.36,9.14$, and $14.06 \mathrm{ng} / \mathrm{ml}$ after 12, 24, and 36 months of $1200 \mathrm{mg} /$ day, respectively. Thus, the total $\mathrm{CoQ}_{10}$ levels in CSF gradually increased after resuming ubiquinol supplementation at $1200 \mathrm{mg}$ /day for the following period (Table 1).

The patient continued to take $1200 \mathrm{mg}$ of ubiquinol/day for over 3 years (Fig. 1). During the entire course, we did not observe any adverse events that were considered to be associated with the ubiquinol supplementation throughout the entire study period. After 36 months of supplementation, evaluation of scores of clinical rating scales (Barthel index, SARA, ICARS, and UMSARS) showed no remarkable changes (Table 2). The brain MRI findings also remained unchanged for the 3 years (Fig. 2). It was notable that his serum creatinine level gradually declined over 36 months (from 1.45 to $0.95 \mathrm{mg} / \mathrm{dl}$ ) (Fig. 1). His body weight decreased in the first 16 weeks $(48.5$ to $41.0 \mathrm{~kg}$ ), but gradually increased over 36 months (41.0 to $46.0 \mathrm{~kg}$ ) after increasing his daily calorie intake (from 900 to $1500 \mathrm{kcal} /$ day).

Table 2 Scores of clinical rating scales

\begin{tabular}{|c|c|c|c|c|c|c|c|}
\hline & $\begin{array}{l}\text { Barthel } \\
\text { index }\end{array}$ & SARA & $\begin{array}{l}\text { ICARS } \\
\text { (dynamic) }\end{array}$ & $\begin{array}{l}\text { ICARS } \\
\text { (static) }\end{array}$ & $\begin{array}{l}\text { UMSARS } \\
\text { Part I }\end{array}$ & $\begin{array}{l}\text { UMSARS } \\
\text { Part II }\end{array}$ & $\begin{array}{l}\text { UMSARS } \\
\text { Part IV }\end{array}$ \\
\hline Before supplementation & 0 & 40 & 50 & 34 & 47 & 49 & 5 \\
\hline After a 2-week supplementation at $600 \mathrm{mg} /$ day & 0 & 40 & 50 & 34 & 47 & 47 & 5 \\
\hline After a 4-week supplementation at $840 \mathrm{mg} /$ day & 0 & 40 & 50 & 34 & 47 & 51 & 5 \\
\hline After a 2-week supplementation at $1200 \mathrm{mg} /$ day & 0 & 39 & 50 & 34 & 47 & 49 & 5 \\
\hline After a 6-month supplementation at $1200 \mathrm{mg}$ /day & 0 & 39 & 51 & 34 & 47 & 50 & 5 \\
\hline After a 12 -month supplementation at $1200 \mathrm{mg}$ /day & 0 & 39 & 51 & 34 & 47 & 51 & 5 \\
\hline After an 18-month supplementation at $1200 \mathrm{mg}$ /day & 0 & 40 & 52 & 34 & 47 & 51 & 5 \\
\hline After a 24-month supplementation at $1200 \mathrm{mg}$ /day & 0 & 40 & 51 & 34 & 47 & 50 & 5 \\
\hline After a 30-month supplementation at $1200 \mathrm{mg}$ /day & 0 & 40 & 50 & 34 & 47 & 49 & 5 \\
\hline After a 36-month supplementation at $1200 \mathrm{mg}$ /day & 0 & 40 & 50 & 34 & 47 & 49 & 5 \\
\hline
\end{tabular}


Fig. 2 Brain MR images of patient. Upper images were obtained at 60 years of age (before supplementation of ubiquinol), and lower images were obtained at 63 years of age (after 36 months of ubiquinol $1200 \mathrm{mg} /$ day). T1-weighted sagittal images (left) and T2-weightd axial images at the middle regions of the pontine base (right). They show gross atrophy of the infratentorial structures especially in the pons, middle cerebellar peduncle, and cerebellum

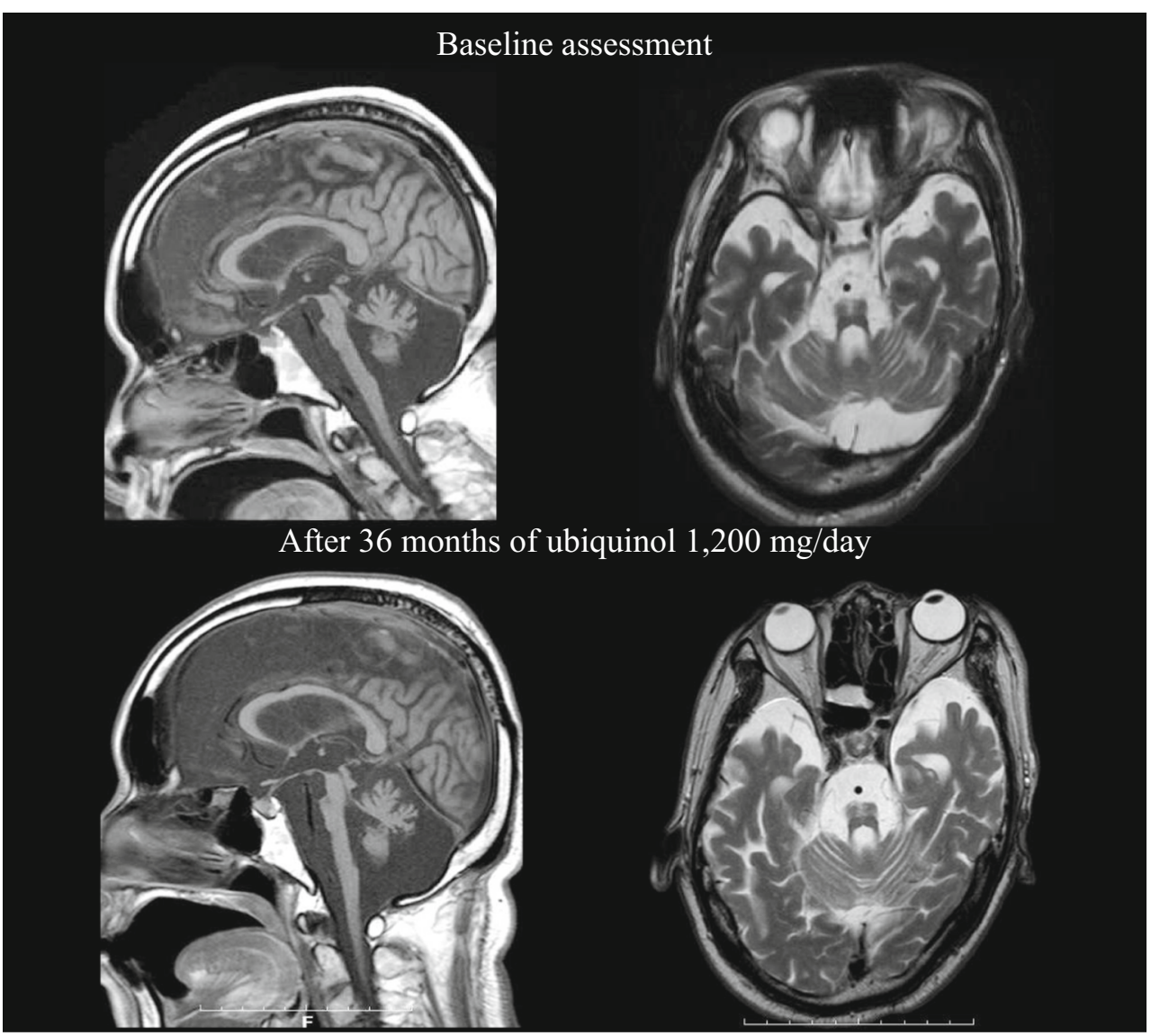

\section{Measurement of the $\mathrm{CBF}$ and the $\mathrm{CMRO}_{2}$ by PET}

Figures 3 and 4 show $\mathrm{CBF}$ and $\mathrm{CMRO}_{2}$ images, respectively, and Table 3 summarizes the quantitative measurements before and after 2 weeks of ubiquinol supplementation at $1200 \mathrm{mg} /$ day. At the baseline, $\mathrm{CBF}$ decreased and $\mathrm{CMRO}_{2}$ markedly decreased in the entire brain. For example, the $\mathrm{CBF}$ and $\mathrm{CMRO}_{2}$ in the Rolandic area were $30.6 \mathrm{ml} / 100 \mathrm{ml} / \mathrm{min}$ [reference level [19], 44.6, 5.6 (mean, standard deviation)] and $1.81 \mathrm{ml} / 100 \mathrm{ml} / \mathrm{min}$ [reference level [19], 3.3, 0.5 (mean, standard deviation)], respectively. After 2 weeks of ubiquinol supplementation at $1200 \mathrm{mg} /$ day, CBF remained unchanged as compared with the baseline level (Fig. 3 and Table 3). In contrast, the $\mathrm{CMRO}_{2}$ markedly increased by approximately $30 \%$ in the entire brain (Fig. 4 and Table 3), although it did not reach normal levels. For example, the $\mathrm{CMRO}_{2}$ in the Rolandic area increased from 1.81 to $2.15 \mathrm{ml} / 100 \mathrm{ml} / \mathrm{min}$ [reference level, 3.3, 0.5 (mean, standard deviation) [19]].

\section{Discussion}

In the present single case study of a patient with familial MSA carrying compound heterozygous mutations in COQ2, administration of high-dose ubiquinol led to a substantial increase in the total $\mathrm{CoQ}_{10}$ levels not only in the plasma and PBMC but also in the CSF. Although previous reports have failed to show the increase in total $\mathrm{CSF}_{\mathrm{CoQ}} \mathrm{Q}_{10}$ level by ubiquinone or ubiquinol supplementation, which was caused possibly due to the insufficient dose (300 mg/day) [25], this is the first study showing that ubiquinol supplementation at 840 and $1200 \mathrm{mg} /$ day clearly elevated the total $\mathrm{CSF} \mathrm{CoQ}_{10}$ level. $\mathrm{CoQ}_{10}$ has been reported to be poorly absorbed, and its bioavailability varies among formulations [26]. Previous dose escalation studies (up to $3000 \mathrm{mg} /$ day) using chewable tablets of ubiquinone in patients with Parkinson disease, amyotrophic lateral sclerosis, and Huntington disease concordantly showed that the total plasma $\mathrm{CoQ}_{10}$ levels reached the plateau levels of approximately $7.0-7.5 \mu \mathrm{g} / \mathrm{ml}$ after multiple doses of 


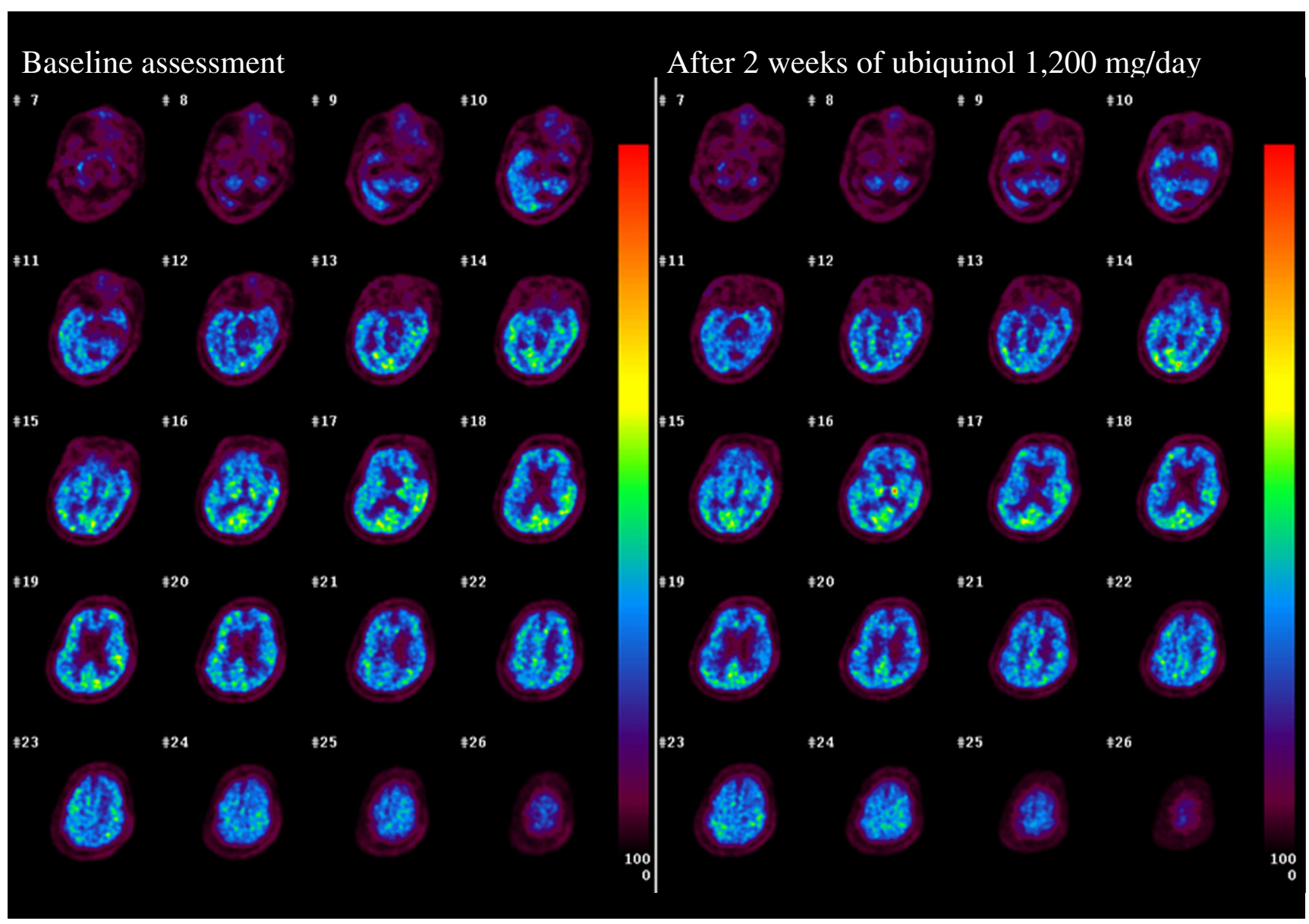

Fig. 3 CBF images before and after ubiquinol supplementation at $1200 \mathrm{mg} /$ day

$2400 \mathrm{mg} /$ day [22-24]. When assessing the bioavailability of ubiquinol in this study, the trough concentrations of total $\mathrm{CoQ}_{10}$ in plasma were $5.04 \mu \mathrm{g} / \mathrm{ml}$ for $600 \mathrm{mg} /$ day, $4.02 \mu \mathrm{g} /$ $\mathrm{ml}$ for $840 \mathrm{mg} / \mathrm{day}$, and $7.86 \mu \mathrm{g} / \mathrm{ml}$ for $1200 \mathrm{mg} /$ day 2 weeks after the daily intake of ubiquinol. Furthermore, another previous study using ubiquinol showed that mean total plasma $\mathrm{CoQ}_{10}$ levels were $2.61 \mu \mathrm{g} / \mathrm{ml}$ for $90 \mathrm{mg} / \mathrm{day}, 3.66 \mu \mathrm{g} / \mathrm{ml}$ for $150 \mathrm{mg} /$ day, and $6.53 \mu \mathrm{g} / \mathrm{ml}$ for $300 \mathrm{mg} /$ day 2 weeks after a daily intake of ubiquinol [27]. These observations indicate that ubiquinol is better absorbed in the gastrointestinal tract than ubiquinone, and we conclude that the ubiquinol dose of $1200 \mathrm{mg} /$ day is sufficient for achieving a plateau of total $\mathrm{CoQ}_{10}$ level in plasma.

Remarkably, $\mathrm{CMRO}_{2}$ increased without an increase in CBF after administration of $1200 \mathrm{mg}$ of ubiquinol, which suggests that ubiquinol improved cerebral mitochondrial oxidative metabolism. Despite the increase in the $\mathrm{CMRO}_{2}$, however, we did not detect any obvious neurological improvements as determined by the rating scales, presumably owing to the advanced stage of neurodegeneration. Notably, his serum creatinine level gradually declined during the ubiquinol supplementation over 36 months (from 1.45 to $0.95 \mathrm{mg} / \mathrm{dl}$ ). Because renal involvement has been frequently observed in patients with primary $\mathrm{CoQ}_{10}$ deficiency caused by genetic defects in $\mathrm{CoQ}_{10}$ biosynthesis [28-30], the renal dysfunction in the patient was likely caused by $\mathrm{CoQ}_{10}$ deficiency and was ameliorated by ubiquinol supplementation. He also showed weight loss in the first 16 weeks of supplementation (48.5 to $41.0 \mathrm{~kg}$ ). We extensively investigated the cause of his weight loss. However, we did not find chronic infectious diseases, malignancies, extremity edema, pleural effusion, or ascites in this patient during the entire study period. He gradually regained his body weight over 36 months ( 41.0 to $46.0 \mathrm{~kg}$ ) after increasing his daily calorie intake. Despite the body weigh changes, his general health condition remained stable.

\section{Conclusions}

The current study suggests that high-dose ubiquinol supplementation (up to $1200 \mathrm{mg} /$ day) is tolerable and improves cerebral mitochondrial oxidative metabolism, which may alter 


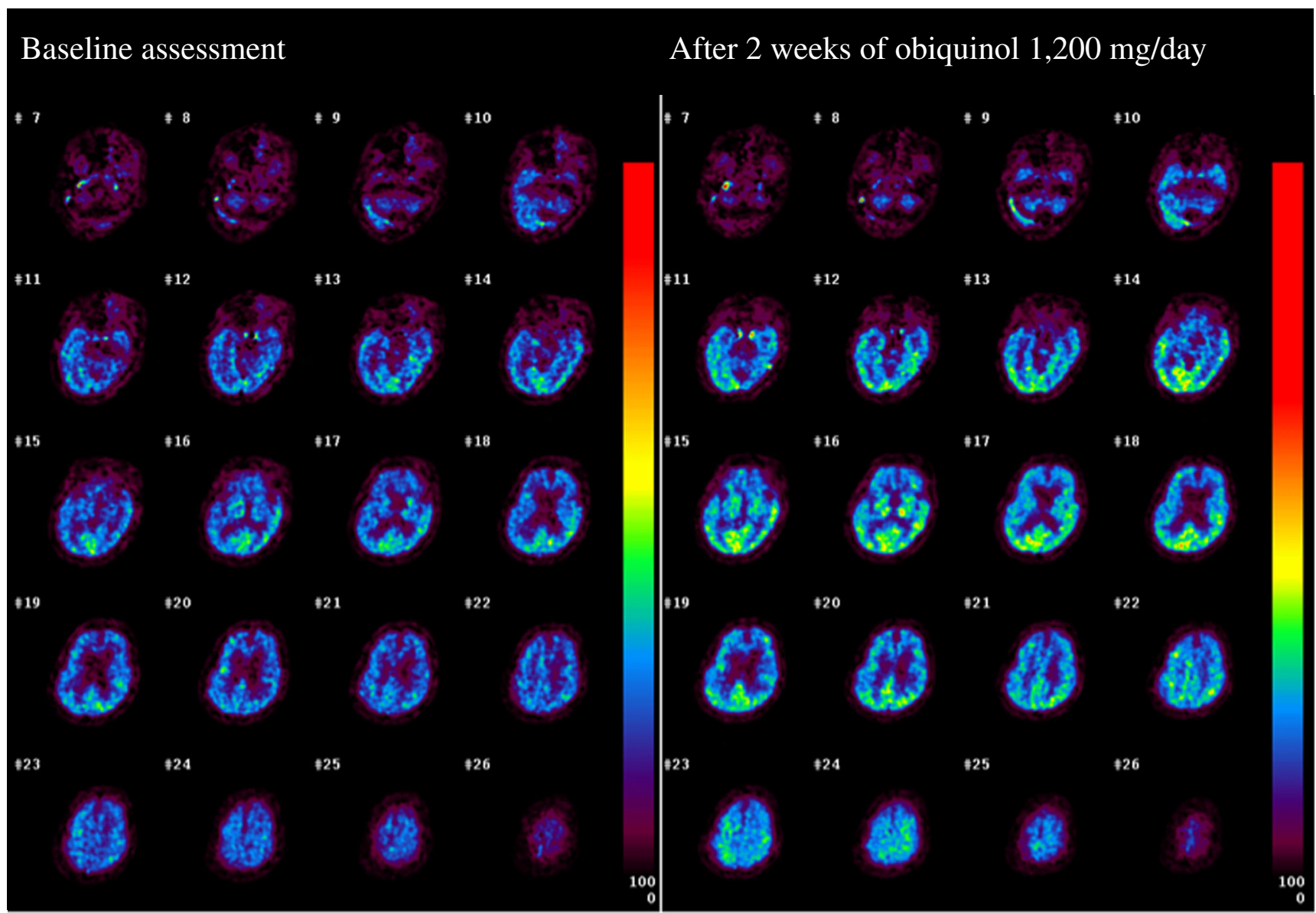

Fig. $4 \mathrm{CMRO}_{2}$ images before and after ubiquinol supplementation at $1200 \mathrm{mg} / \mathrm{day}$

the natural history of MSA progression especially when applied in the early phase of MSA in patients with genetic defects in the $\mathrm{CoQ}_{10}$ biosynthetic pathway. Further clinical trials including administration of ubiquinol to MSA patients carrying heterozygous $C O Q 2$ mutations as well as to patients without mutations in $C O Q 2$ are warranted. Prospective randomized controlled trials will be undertaken to further extend these initial promising observations.
Table $3 \mathrm{CBF}$ and $\mathrm{CMRO}_{2}$ in major brain areas before and after ubiquinol supplementation

\begin{tabular}{lcccc}
\hline & $\mathrm{CBF}(\mathrm{ml} / 100 \mathrm{ml} / \mathrm{min})$ & $\mathrm{CMRO}_{2}(\mathrm{ml} / 100 \mathrm{ml} / \mathrm{min})$ \\
\hline Region & Before & After & Before & After \\
Upper frontal & 28.8 & 27.7 & 1.78 & 2.17 \\
Lower frontal & 29.7 & 29.8 & 1.72 & 2.23 \\
Rolandic & 30.6 & 29.7 & 1.81 & 2.15 \\
Lateral parietal & 30.8 & 29.9 & 2.03 & 2.52 \\
Medial parietal & 35.3 & 42.1 & 2.05 & 3.12 \\
Temporal & 31.5 & 30.3 & 2.11 & 2.65 \\
Occipital & 38.2 & 37.5 & 2.63 & 3.17 \\
Striatum & 30.4 & 29.7 & 1.92 & 2.56 \\
Thalamus & 35.3 & 44.5 & 2.08 & 3.20 \\
Cerebellar hemisphere & 24.3 & 24.3 & 1.44 & 1.89 \\
Cerebellar vermis & 23.7 & 22.4 & 1.33 & 1.58 \\
\hline
\end{tabular}


Acknowledgements We thank Midori Nagase for her technical assistance. This study was supported in part by KAKENHI [Grant-in-Aid for Scientific Research on Innovative Areas (22129001 and 22129002)] to S.T. from the Ministry of Education, Culture, Sports, Science and Technology of Japan, and a Grant-in-Aid [H23-Jitsuyoka (Nanbyo)Ippan-004 and "the Research Committee for Ataxic Diseases" of the Research on Measures for Intractable Diseases] from the Ministry of Health, Welfare and Labour, Japan, to S.T. Ubiquinol in the powder form (Kaneka QH ubiquinol) was provided by Kaneka Corporation (Tokyo, Japan).

Compliance with Ethical Standards The protocol of this study (UMIN000010712) was reviewed and approved by the institutional review board of the participating institutions. Informed consent was obtained from the patient and his legal representative prior to the initiation of this study, in accordance with the Declaration of Helsinki.

Conflict of Interest The authors declare that they have no conflict of interest.

Open Access This article is distributed under the terms of the Creative Commons Attribution 4.0 International License (http:// creativecommons.org/licenses/by/4.0/), which permits unrestricted use, distribution, and reproduction in any medium, provided you give appropriate credit to the original author(s) and the source, provide a link to the Creative Commons license, and indicate if changes were made.

\section{References}

1. Gilman S, Wenning GK, Low PA, Brooks DJ, Mathias CJ, Trojanowski JQ, et al. Second consensus statement on the diagnosis of multiple system atrophy. Neurology. 2008;71:670-6.

2. The Multiple-System Atrophy Research Collaboration. Mutations in COQ2 in familial and sporadic multiple-system atrophy. N Engl J Med. 2013;369:233-44.

3. Ashby MN, Kutsunai SY, Ackerman S, Tzagoloff A, Edwards PA. COQ2 is a candidate for the structural gene encoding parahydroxybenzoate:polyprenyltransferase. J Biol Chem. 1992;267: 4128-36.

4. Littarru GP, Tiano L. Bioenergetic and antioxidant properties of coenzyme Q10: recent developments. Mol Biotechnol. 2007;37: 31-7.

5. Lagier-Tourenne C, Tazir M, Lopez LC, Quinzii CM, Assoum M, Drouot N, et al. ADCK3, an ancestral kinase, is mutated in a form of recessive ataxia associated with coenzyme Q10 deficiency. Am J Hum Genet. 2008;82:661-72.

6. Mollet J, Delahodde A, Serre V, Chretien D, Schlemmer D, Lombes $\mathrm{A}$, et al. $\mathrm{CABC} 1$ gene mutations cause ubiquinone deficiency with cerebellar ataxia and seizures. Am J Hum Genet. 2008;82:623-30.

7. Pineda M, Montero R, Aracil A, O'Callaghan MM, Mas A, Espinos $\mathrm{C}$, et al. Coenzyme Q(10)-responsive ataxia: 2-year-treatment follow-up. Mov Disord. 2010;25:1262-8.

8. Liu YT, Hersheson J, Plagnol V, Fawcett K, Duberley KE, Preza E, et al. Autosomal-recessive cerebellar ataxia caused by a novel ADCK3 mutation that elongates the protein: clinical, genetic and biochemical characterisation. J Neurol Neurosurg Psychiatry. 2014;85:493-8.

9. Mignot C, Apartis E, Durr A, Marques Lourenço C, Charles P, Devos D, et al. Phenotypic variability in ARCA2 and identification of a core ataxic phenotype with slow progression. Orphanet J Rare Dis. $2013 ; 8: 173$
10. Rotig A, Appelkvist EL, Geromel V, Chretien D, Kadhom N, Edery $\mathrm{P}$, et al. Quinone-responsive multiple respiratory-chain dysfunction due to widespread coenzyme Q10 deficiency. Lancet. 2000;356: $391-5$.

11. Van Maldergem L, Trijbels F, DiMauro S, Sindelar PJ, Musumeci O, Janssen A, et al. Coenzyme Q-responsive Leigh's encephalopathy in two sisters. Ann Neurol. 2002;52:750-4.

12. Hara K, Momose Y, Tokiguchi S, Shimohata M, Terajima K, Onodera $\mathrm{O}$, et al. Multiplex families with multiple system atrophy. Arch Neurol. 2007;64:545-51.

13. Mahoney FI, Barthel DW. Functional evaluation: the Barthel index. Md State Med J. 1965;14:61-5.

14. Schmitz-Hübsch T, du Montcel ST, Baliko L, Berciano J, Boesch S, Depondt $\mathrm{C}$, et al. Scale for the assessment and rating of ataxia: development of a new clinical scale. Neurology. 2006;66:1717-20.

15. Trouillas P, Takayanagi T, Hallett M, Currier RD, Subramony SH, Wessel K, et al. International Cooperative Ataxia Rating Scale for pharmacological assessment of the cerebellar syndrome. The Ataxia Neuropharmacology Committee of the World Federation of Neurology. J Neurol Sci. 1997;145:205-11.

16. Wenning GK, Tison F, Seppi K, Sampaio C, Diem A, Yekhlef F, et al. Development and validation of the Unified Multiple System Atrophy Rating Scale (UMSARS). Mov Disord. 2004;19:1391402.

17. Yamashita S, Yamamoto Y. Simultaneous detection of ubiquinol and ubiquinone in human plasma as a marker of oxidative stress. Anal Biochem. 1997;250:66-73.

18. Frackowiak RS, Lenzi GL, Jones T, Heather JD. Quantitative measurement of regional cerebral blood flow and oxygen metabolism in man using 150 and positron emission tomography: theory, procedure, and normal values. J Comput Assist Tomogr. 1980;4:727-36.

19. Ito H, Kanno I, Kato C, Sasaki T, Ishii K, Ouchi Y, et al. Database of normal human cerebral blood flow, cerebral blood volume, cerebral oxygen extraction fraction and cerebral metabolic rate of oxygen measured by positron emission tomography with 15O-labelled carbon dioxide or water, carbon monoxide and oxygen. Eur J Nucl Med Mol Imaging. 2004;31:635-43.

20. Martin WR, Powers WJ, Raichle ME. Cerebral blood volume measured with inhaled $\mathrm{C} 15 \mathrm{O}$ and positron emission tomography. J Cereb Blood Flow Metab. 1987;7:421-6.

21. Lammertsma AA, Jones T. Correction for the presence of intravascular oxygen- 15 in the steady-state technique for measuring regional oxygen extraction ratio in the brain: 1. Description of the method. J Cereb Blood Flow Metab. 1983;3:416-24.

22. Shults CW, Flint Beal M, Song D, Fontaine D. Pilot trial of high dosages of coenzyme Q10 in patients with Parkinson's disease. Exp Neurol. 2004;188:491-4.

23. Hyson HC, Kieburtz K, Shoulson I, McDermott M, Ravina B, de Blieck EA, et al. Safety and tolerability of high-dosage coenzyme Q10 in Huntington's disease and healthy subjects. Mov Disord. 2010;25:1924-8.

24. Ferrante KL, Shefner J, Zhang H, Betensky R, O’Brien M, Yu H, et al. Tolerance of high-dose (3,000 mg/day) coenzyme Q10 in ALS. Neurology. 2005;65:1834-6.

25. Lönnrot K, Metsä-Ketelä T, Molnár G, Ahonen JP, Latvala M, Peltola J, et al. The effect of ascorbate and ubiquinone supplementation on plasma and CSF total antioxidant capacity. Free Radic Biol Med. 1996;21:211-7.

26. Bhagavan HN, Chopra RK. Plasma coenzyme Q10 response to oral ingestion of coenzyme Q10 formulations. Mitochondrion. 2007;7(Suppl):S78-88.

27. Hosoe K, Kitano M, Kishida H, Kubo H, Fujii K, Kitahara M. Study on safety and bioavailability of ubiquinol (Kaneka QH) after single and 4-week multiple oral administration to healthy volunteers. Regul Toxicol Pharmacol. 2007;47:19-28. 
28. Lopez LC, Schuelke M, Quinzii CM, Kanki T, Rodenburg RJ, Naini A, et al. Leigh syndrome with nephropathy and CoQ10 deficiency due to decaprenyl diphosphate synthase subunit 2 (PDSS2) mutations. Am J Hum Genet. 2006;79:1125-9.

29. Quinzii C, Naini A, Salviati L, Trevisson E, Navas P, Dimauro S, et al. A mutation in para-hydroxybenzoate-polyprenyl transferase (COQ2) causes primary coenzyme Q10 deficiency. Am J Hum Genet. 2006;78:345-9.
30. Diomedi-Camassei F, Di Giandomenico S, Santorelli FM, Caridi G, Piemonte F, Montini G, et al. COQ2 nephropathy: a newly described inherited mitochondriopathy with primary renal involvement. J Am Soc Nephrol. 2007;18:2773-80.

31. Mitsui J, Matsukawa T, Yasuda T, Ishiura H, Tsuji S. Plasma coenzyme Q10 levels in patients with multiple system atrophy. JAMA Neurol. 2016;73:977-80. 